Article

\title{
Hydrological Modeling in Tropical Regions via TopModel. Study case: Central Sector of the Middle Magdalena Valley - 5 Colombia
}

\author{
Arenas-Bautista, M. C. ${ }^{1}$, Arboleda-Obando, P. F², Duque-Gardeazabal, N. ${ }^{2}$, Saavedra-Cifuentes, E. ${ }^{1}$, Donado, L. \\ $\mathrm{D}^{1}$ \\ ${ }^{1}$ Hyds, Hydrodynamics of the Natural Media Research Group, Universidad Nacional de Colombia. Sede Bogotá, \\ ${ }^{2}$ Gireh, Water Resources Engineering Research Group, Universidad Nacional de Colombia. Sede Bogotá, Colombia. \\ Correspondence to: Arenas-Bautista, M. C (mcarenasb@unal.edu.co)
} 10 Colombia.

Abstract - Hydrological modeling allows us to make a comprehensive assessment of the interaction between dynamics of the hydrological cycle, climate conditions, and land use. These modeling results are relevant in water resources management field. We use TopModel (TOPography based hydrological MODEL for the hydrological modeling of an area of $17000 \mathrm{~km}^{2}$ in the Middle Magdalena Valley (MMV), a tropical basin located in Colombia. This study is located in the intertropical convergence zone (ITCZ) which is characterized by special meteorological conditions and fast water fluxes over the year. This area has been subjected to significant land use changes, as a result of intense economic activities, e.g., agriculture, hydropower energy and oil \& gas production (Avellaneda, 2003). The proposed model is based on a record of 12 years of: i.) daily precipitation data from observed gauges, ii.) daily evapotranspiration data from temperature data and iii.) daily streamflow data as observed data. A calibration process was performed using data from 2000 to 2008, and a validation was performed with data from 2009 to 2012. The Nash-Sutcliffe coefficient was used as an objective function to assess the quality of these processes (values of this metric are between 0.74 and 0.73 respectively, for model calibration and validation). The results show us an adequate performance of the model in areas of the tropical region and allow us to analyze the relationship between water storage capacity in the soils of the area with subsurface runoff. This conclusion is consistent with the characteristics of the region. The calibrated model provides an idea about the hydrological functioning of the basin and estimates an approximation of the groundwater recharge in the region. The estimation of the recharge is important to quantify the interaction of surface water and groundwater, especially during the dry season, due to its importance in the analysis of scenarios with climate variability.

Keywords-Hydrologic modeling, TopModel, Middle Magdalena Valley, Nash Sutcliffe efficiency, Tropical regions. 


\section{INTRODUCTION}

In the last decade, mathematical models are getting an important role for solving problems in water resources management (Dunne, 1983; Reynaud and Leenhardt, 2008; Bossa et al., 2012), giving rise to discussions about their use and application to evaluate and analyze complex hydrological systems (Bellin et al., 2016).

Hydrological models have been developed to understand different processes. This processes must be evaluated for different environmental conditions (Jenson, 1991; Loosvelt et al., 2014; Hollanda et al., 2015). However, they are generally focused on fulfilling two main objectives: i) to improve the understanding of the hydrological phenomena in the basins and how the changes generated in them affect the hydrological phenomena and, ii) the generation of synthetic sequences of hydrological data for the design of infrastructure or for its use in forecasting (Refsgaard, 1997; Kauffeldt et al., 2016; Ibarra-Zavaleta et al., 2017).

These models are classified into three types (Sieber et al., 2005; Hughes, 2016): i) Empirical: where the solution is based on empirical parameters, calculated by identifying statistically significant relationships between certain variables; ii) Theoretical: that are described by differential equations and follow the laws of physical and chemical processes; and iii) Conceptual: which are simplified representations of physical processes, in mathematical terms to simulate complex processes based on key parameters that describe the important functions of the system of interest.

In this research we implemented a rainfall-runoff model as TopModel (Lamb, Beven and Myrabø, 1998; Beven and Freer, 2001b)). TopModel us usually applied to assess the management of water resources at the regional scale, using conceptual models for detailed assessment of surface flow (Beven and Freer, 2001a; Mockler, O'Loughlin and Bruen, 2016; Teng et al., 2017). Likewise, distributed and semi-distributed models (which do not simulate the basin as a group, but as a set of divided parts) are necessary for the simulation of spatial patterns of hydrological response within a basin (Mazzoleni et al., 2015; Ibarra-Zavaleta et al., 2017) . Moreover, hydrological models also provide valuable information to study changes in land use or climate (Karlsson et al., 2016). Thus, changes in land use are directly related to water supply (and therefore to hydrological modeling), mainly related to human consumption, food production, and power generation. These activities have become a global priority in the economic and social sphere due to the growth of the population and the need to establish economic activities for the communities' empowerment (Harou et al., 2009; Buytaert, 2011; Crespo et al., 2012). Through models, it has been possible to represent dominant hydrological processes in the hydrological cycle of a particular ecosystem, mainly by calculating the water balances which allow exploring the validity of the representation, interactions and various levels of model behavior (Buytaert and Beven, 2011). 
The more the basic hydrological information (precipitation, temperature, evaporation, evapotranspiration and flow), the more the objectives of the hydrological models achieved. However, the uncertainty due to scarcity of these data is quite common in several areas of Colombia, due to the complexity of the topography (Meerveld and Weiler, 2008). In addition, it is necessary to generate tools for calibration and validation of synthetic data to the hydrological modeling process (Blanco-Gutiérrez, Varela-Ortega and Purkey, 2013; da Silva et al., 2015). The calibration and validation of data through modeling, has enabled the verification of the assumptions that underlie the hydrological model used, which has contributed significantly to the generation of new knowledge (IbarraZavaleta et al., 2017).

In consequence, basin-scale hydrological modeling lead us to an analysis of the spatial variability in a simplified way of the hydrological response (Beven and Freer, 2001a). Models based on topography in a region such as the MMV allows us to conclude the information of the topographic index (used to quantify topographic control on hydrological processes) is integrated into the general structure of the model, throughout the spatial distribution of moisture content and water table depth (Mukherjee et al., 2013).

This document presents a simplified description of the TopModel applied in the Southern part of the MMV area and a general description of the methods used for its evaluation. This paper is organized as follows: Section 2 presents the theoretical framework. Section 3 shows the area of study. Section 4 presents the data sources. Section 5 illustrates the calibration and validation results and conclusions are indicated in Section 6.

\section{THEORETICAL FRAMEWORK}

\subsection{Hydrologic Model: TopModel}

TopModel is a semi-distributed model based on similarities of the topography which are expressed through a Topographic Index (TWI). It can be considered as a rainfall-runoff conceptual model based on the landscape characteristics which contains three dynamic storage regions: i) root zone, ii) gravity zone and iii) saturated zone (Hollanda et al., 2015; Metcalfe, Beven and Freer, 2015) (figure 1). The main assumptions of the model are:

i. The dynamics of the saturated zone can be approached through a steady state simulation,

ii. All the model parameters are spatially homogeneous,

iii. The hydraulic gradient can be approximated via the surface terrain gradient,

iv. The hydraulic conductivity decreases exponentially with depth. 
The model theory assumes that the local hydraulic gradient is equal to the local surface slope and implies that all points with the same value of the TWI have the same hydraulic properties (Andersen, Refsgaard and Jensen, 2001; Mukherjee et al., 2013; Yi, Zhang and Yan, 2017; Jeziorska and Niedzielski, 2018). Its value is computed from the basin topography using [1].

$$
T W I_{i}=\ln \frac{a_{i}}{\tan \beta_{i}}
$$

95 where $a_{i}$ is the upslope contributing area of $\mathrm{i}$-th basin and $\tan \beta_{i}$ is the slope of the ground surface of the basin. Upslope contributing area represents the area that can potentially produce runoff to the point of interest (Suliman et al., 2016; Jeziorska and Niedzielski, 2018).

The generation of runoff in TopModel is given by a relation between the topography and the transmissivity of the basin (Dewandel et al., 2017; Jeziorska and Niedzielski, 2018; Xue et al., 2018). Rain infiltrates the root zone (figure 100 1) until its maximum storage capacity is reached, and then it can be reduced to a linear velocity by the actual evapotranspiration of the surface, described by [2].

$$
E_{a}=E_{p}\left(1-\frac{S_{r z}}{S_{r \max }}\right)
$$

where $E_{a}$ is the real evapotranspiration, $E_{p}$ is the potential evapotranspiration, $S_{r \max }$ is the maximum root zone deficit and $S_{r z}$ is the root zone deficit.

After the infiltration process in the root zone ends, the excess water fills the unsaturated zone and recharges the saturated zone generating a decrease in the water table depth. According to the first assumption of TopModel, the depth of the local water table is represented by the local storage deficit (D), which can be calculated for each $T W I$ class using [3].

$$
D_{l}=D+m\left(\alpha-T W I_{i}\right)
$$

where $D_{l}$ is the catchment average water table depth, $\alpha$ is the average TWI and $m$ is scaling parameter.

The water table is equal to the ground level when reaches zero. Therefore, the average value of the TWI for which constitutes the threshold for the maximum storage capacity. Moreover, each point having higher value of TWI is 
considered to be in a saturation condition. Additional rain on saturated surfaces cannot infiltrate the soil, therefore, excess water is transferred directly to saturated surface runoff.

The water storage deficit is reduced by the recharge water flux from the unsaturated zone to the groundwater, and its rate can be calculated using [4]:

$$
q_{v}=\frac{S_{u z}}{D_{l} T_{d}}
$$

115 where $D_{l}$ is the local storage deficit, $S_{u z}$ is the local water storage in the unsaturated zone and $T_{d}$ is the mean residence time in the $S_{u z}$. Therefore, the total recharge rate $q_{v}$ is expressed as the sum of all values of $q_{v_{i}}$ multiplied by the upslope area $A_{i}$ representing a set of hydrologically homogenous points, associated with topographic index class of the i-th location (Metcalfe, Beven and Freer, 2015).

$$
Q_{v}=\sum_{i=1}^{n} q_{v_{i}} A_{i}
$$

where $Q_{v}$ the total flux, $q_{v_{i}}$ the flux of water entering the water table locally (per unit area).

120 The base flow $Q_{b}$ is represented as the subsurface saturated zone flux $q_{s}$, and can be defined by [6]:

$$
Q_{b}=q_{s}=Q_{0} e^{\left(-\frac{D}{m}\right)}
$$

Where $Q_{0}$ is the hydrological flux for the entire catchment area when $D=0$. Both above described components: surface flow $q_{s}$ and base flow $Q_{b}$ account for the total discharge.

Consequently, the total runoff at the outlet of the basin is expressed as the sum of the surface flow and the base flow (van der Heijden and Haberlandt, 2015). The transmissivity - $T$ in the low zones [7], according to the fourth 
125 assumption of TopModel, decreases with the depth following the negative exponential law versus the saturation deficit $D$ being $m$ a recession parameter (Ahmed Suliman et al., 2014).

$$
T=T_{0} e^{\left(-\frac{D}{m}\right)}
$$

where $T_{0}$ the local saturated transmissivity.

\subsection{Calibration and Validation}

Calibration is the procedure adopted to obtain a set of optimal parameters and initial values that are adjusted to the particular characteristics of each basin (Dakhlaoui et al., 2017). The Nash Sutcliffe objective function - NSE [8] (Wu et al., 2017) is considered a test for the goodness of fit of the hydrological prediction model, got by comparing between observed and simulated discharges (Dakhlaoui et al., 2017). Measured discharge was used as indicative variable, to be compared with model predictions of discharge, through the studied period.

$$
N S E=1-\frac{\sum_{i=1}^{n}\left(Q_{i}-S_{i}\right)^{2}}{\sum_{i=1}^{n}\left(Q_{i}-\widehat{O}_{i}\right)^{2}}
$$

where $Q_{i}$ represents the observed flow, $S_{i}$ is the simulated flows and $\widehat{O}_{i}$ the average of observed flows.

135 In addition, the percentage bias (PBIAS) is used as a complement in the analysis of the performance of the model to measure the average tendency of the simulated values to be larger or smaller than those observed (Wiant and Harner, 1979). The optimal value of the PBIAS is 0 , the positive values indicate an overestimation bias and the 
negative values indicate a bias of underestimation of the model. The equation used for its calculation is shown in [9].

$$
P B I A S=\frac{100 \sum_{i=1}^{n}\left(S_{i}-Q_{i}\right)}{\sum_{i=1}^{n} Q_{i}}
$$

140 Validation allows to determine how accurate the model reproduces or imitates independent information using the values of the parameters found during calibration (Refsgaard, 1997; Devia, Ganasri and Dwarakish, 2015; Y. Zhang et al., 2016).

\section{STUDY AREA}

The study area (figure 2A) covers $17,000 \mathrm{~km}^{2}$ of the central area of the MMV and is geomorphologically located 145 along the central part of the valley, crossed by the Magdalena River, between the eastern and central mountain ranges of the Colombian Andes (Avellaneda, 2003). The Magdalena River has a length of approximately $650 \mathrm{~km}$ along the studied area. This region is rich in natural ecosystem resources, such as fresh water, flora and fauna and mineral resources such as gold, oil and gas (Ingrain, 2012). The study area is hydrologically formed by five basins associated with the water potential of the Magdalena River and its most important tributaries (Cimitarra,

150 Sogamoso, Opon, Carare and Negro Rivers) (Ideam, 2014). In this area, rainfall has a bimodal pattern: a first season between March and June and a second season between October and December; the rest of the year is dry (Ideam, 2014). The average amount of rain exceeds $2,000 \mathrm{~mm} /$ year and the river has an average annual flow of $2,361 \mathrm{~m}^{3} / \mathrm{s}$ and high flows (Q5) of 4,298 m³ $/ \mathrm{s}$ and low (Q95) of $1,578 \mathrm{~m}^{3} / \mathrm{s}$. The average annual temperature is higher than $24{ }^{\circ} \mathrm{C}$ throughout the territory and the elevation of the terrain varies between 16 and 3110 meters above sea level (Ideam, 2014).

The most important economic activity in the study area is the extraction, production and transportation of oil and gas (Jaime Herrera et al., 2013). In addition, the study area is an important crossroads between the Andes, the capital and the most populous city of Colombia, Bogotá and the Caribbean ports in the north of the country (Asociacion Colombiana del Petroleo and Asociacion Latinoamericana de la Industria Petrolera, 2008).

\section{DATA SOURCES}

A digital elevation model (DEM) (figure 2A) was derived from SRTM satellite data with a 30 meters resolution between the coordinates $6^{\circ} 7^{\prime} 46^{\prime \prime} \mathrm{N}$ and $74^{\circ} 39^{\prime} 47^{\prime \prime} \mathrm{W}$ and an average vertical altitude error of $6.2 \mathrm{~m}$ (90\% confidence level) and a geolocation error of 9 meters for South America (Sharma, Tiwari and Bhadoria, 2011).

For the consolidation of the TWI, it was necessary to export the DEM in ASCII format to TopModel using the Sp, Raster and Topidx packages (Metcalfe, Beven and Freer, 2015). The cells with similar hydrological characteristics were generated from the grouping of pixels into different categories based on the function of the topographic index (Dai et al., 2017). The TWI for the study area is presented in figure 3. This map shows a correspondence between the highest values of the index and the drainage network. Areas with TWI values between 15 and 22.5 correspond 
to the location where the drainage network is generated. According to this, the high values of the topographic index are related to areas topographically convergent or smooth slopes which generate discharge flows (Beven and Freer, 2001a). These areas are characterized by low transmissivities, thus the level of water table reaching the surface (Tian, Zheng and Zheng, 2016).

The information of daily rainfall (available at IDEAM) was verified through an analysis of missing data, considering only those stations with less than $10 \%$ of missing data. Then, a $10 \mathrm{~km}$ buffer of $10 \mathrm{~km}$ was set to the study area, from which 37 optimal stations were obtained. The missing data from the chosen stations was completed using the triangulation method with the three closest stations and considering a period between 2000 and 2012. The average precipitation in the basin was estimated by the Thiessen method, as described in Ruelland et al., 2008 and Wagner et al., 2012 (figure 2B) [10].

The calculation of evapotranspiration (ETo) was performed using the Hargreaves method (Hargreaves and Samani, 1982; Hargreaves and Allen, 2003). This method allows to determine the daily air temperature range ( $T R=T_{\max }-T_{\min }$ ) and the extraterrestrial radiation $R_{a}$ to estimate the solar radiation $R_{s^{\prime}}$, as shown in [10].

$$
R_{s}=K_{R S} R_{a} T R^{0.5}
$$

where $R_{s}$ is the solar radiation (mm/d), $K_{R S}$ is an empirical coefficient fitted to $R_{s} / R_{a}$ versus TR data with a value of $0.16, R_{a}$ is extraterrestrial radiation $(\mathrm{mm} / \mathrm{d}), T R$ is daily air temperature range in degrees Celsius. By means of the previous equation we obtain [11] for the calculation of $E T_{0}$.

$$
E T_{0}=C \cdot R_{a}\left(T_{\text {mean }}+a\right) T R^{m}
$$

Where $C, a$ and $m$ are coefficients with values of $0.0023,17.8$ and 0.5 , respectively (Díaz, Esteller and LopezVera, 2005), $T_{\text {mean }}$ is mean air temperature $\left({ }^{\circ} \mathrm{C}\right)$.

For this process, the temperature data was obtained from IDEAM and verified with the procedure described in the previous paragraph for the precipitation data. The observed average temperature of 16 optimal climatologic stations was used in the area of study; its distribution in the basin was estimated by the Thiessen method with correction based on elevation (figure 2C) (Y. Zhang et al., 2016; Ayantobo et al., 2017). Flow data was obtained from IDEA databases as well through the selection of three limnimetric stations. The selection of stations considered two at the inlet (Puerto Berrio and Sogamoso) and one at the outlet of the basin (San Pablo). These stations were selected 
because they were used as a reference in the annual report presented by the Ideam - ENA (Ideam, 2014). Data from 2000 to 2008 was used for the model calibration and data from 2009 to 2012 was used to validate the model.

\section{RESULTS}

\subsection{Parameter estimation}

TopModel uses, in addition to the TWI, ten parameters that represent the characteristics of the basin through hydrology, soils, and location of the study area (Table 1). The values of each of these parameters use reliable 200 information that is available for the study area. In this work, the values of the model parameters were initially established from the reported literature for MMV area by the hydrological and geological institutions of Colombia (National Hydrological, Meteorological and environmental Institute - Ideam, and Colombian geological service SGC) and they are shown in Table 1.

The drawbacks generated by the model in the calibration process are associated with the uncertainty of the parameters because the different sets of possible parameter values can have similar performance values (Loosvelt et al., 2014; Mazzoleni et al., 2015; Ballinas-González, Alcocer-Yamanaka and Pedrozo-Acuña, 2016). For this reason, a Monte Carlo analysis (He et al., 2012; Simmons et al., 2017) has been used to estimate the best sets of parameters that generate a better performance. For this purpose, a data sampling with uniform distribution based on the interval reported in Table 1 was used. The number of simulations varied between 10000 and 35000, since make new 210 iterations did not improve the model performance.

This analysis showed that the parameters $m$ and Srmax are the most significant (figure 4), so the change in their values influences the performance of the model and the shape of the simulated hydrograph. The $m$ parameter represents the change in the saturated hydraulic conductivity with respect to depth. Small values of $\mathrm{m}$ imply quick flow and insignificant subsurface runoff, while large values indicate that more rainfall can infiltrate the soil, thus 215 less water reaches the outlet via surface route (Sigdel et al., 2011). This parameter is related to subsurface flow control and the deficit of local storage, which is important in the case of percolation and recharge of an aquifer (Buytaert and Beven, 2011). Therefore, this parameter has a significant effect on the calculation of the local storage deficit, contributing areas and the shape of the curve in the hydrograph recession.

The value of the Srmax indicates the influence of evapotranspiration on the hydrological behavior of the catchment. 220 Low Srmax value allows less water to be stored in the root zone and hence available for evapotranspiration what can lead to the increased runoff (Hollanda et al., 2015).

\subsection{Model performance}

The model was implemented for 2000-2012 period, with a daily timescale. Data between 2000 and 2008 was used for the calibration of the model, by verifying site conditions adjusted to the structure and model assumptions and the establishment of a set of initial parameters which adequately describes the hydrological behavior of the basin study. During the process of calibration, the values of model parameters were selected which corresponding to the parameter sets with the highest values of efficiencies obtained (i.e. NSE values) in the performed simulations. Initial 
simulations with iterations between 10.000 and 35.000 for data were made, and non-significant differences in values of efficiency were detected when comparing best parameter sets performance.

230 The results from calibration (figure 5) generated a set of parameters with an efficiency of 0.74 for the objective function and 2.6 for PBIAS (table 2). The efficiencies were classified according to the methodology reported by Boskidis et al., 2012. The differences in the efficiencies of the parameter sets were very low, so the overall performance of all simulations can be considered very similar, despite small variations in the values of all parameters that generate these efficiencies. This is associated with the sensitivity of the parameters and their impact on the representation of hydrological processes in the studied basin.

For the process of the model validation, results generated from the calibrated parameters with higher NSE values gave efficiency values near to 0.73 and its simulated flows. The NSE values found are close to the values obtained for a proven models in Ecuador, Colombia, Poland, Nepal and China with efficiency values near to 0.7 (Sigdel et al., 2011; Padrón et al., 2015; Gil Morales and Tobón Marín, 2016; Jeziorska and Niedzielski, 2018; Xue et al., 2018).

240 However, it is possible that longer periods of time could help ensure better simulations and adjustments, because when more data is added to model, the variability increases, and so the parameter values are adjusted in concordance. Additionally, it is widely known that TopModel has problems to accurately represent low flows during droughts (Hollanda et al., 2015). For periods where precipitation exceeds evapotranspiration, the wide range of parameters provide acceptable simulations for basin discharge, although base flow is less accurately simulated, as it happen in other sites (Z. Zhang et al., 2016).

In addition, the performance of the model has been analyzed through the flow duration curve between the observed and simulated data (Badjana et al., 2017)(figure 6). The simulated curve shows an increase of 28 cubic meters per day between $10 \%$ and $90 \%$ of the exceedance time with respect to observed curve, which indicates that its variability is low and therefore it is related to underground storage processes that dominate the flow of the stream and maintain a flow more stable in time (Salazar, 2016). This corroborates the analysis carried out with respect to the variability of the parameters and allows us to identify a coherent process between the behavior of the basin studied and the performance of the model. In particular, it seems that the model fits well the high-flow observations, but presents a slightly higher variance for the mid-flows, as observed in a line with a higher slope; as for the low-flows, the observations is featuring a step at the end of the FDC, indicating that the basin is not able to maintain the same conditions for base flow as for other flow sources, maybe due to anthropic or natural interferences on the percolation fluxes, and simulated flows roughly follows this patterns, with a smoother curve, due to its impossibility to represent these unknown interferences.

\section{CONCLUSION}

TopModel was able to reproduce the main pattern of the hydrograph with acceptable accuracy for the case-study. A low performance to simulate some patterns (base flow) can be attributed to errors in input data and parameter uncertainty. The most probable cause of those results is linked to the uncertainty of the data series analyzed. Low accuracy of the model can also be an effect of the model inability to represent distributed rainfall pattern.

The application of the hydrological model developed in this research contributes to national efforts and the availability of results for the development of comparative studies in Middle Magdalena Valley at basin scale. This 
265 work constitutes a sample of the advantage of applying a widely used semi-distributed model that is freely accessible, contrary to the limitations of using a model that depends on the singularity of the area of study. The results obtained here will be used as input data in a hydrogeological analysis of the area.

\section{REFERENCES}

Ahmed Suliman, A. H. et al. (2014) 'Semi-distributed rainfall-runoff modeling utilizing ASTER DEM in Pinang catchment of Malaysia', Sains Malaysiana, 43(9).

Andersen, J., Refsgaard, J. C. and Jensen, K. H. (2001) ‘Distributed hydrological modelling of the Senegal River Basin - model construction and validation', Journal of Hydrology, 247(3-4), pp. 200-214. doi: 10.1016/S00221694(01)00384-5.

Asociacion Colombiana del Petroleo and Asociacion Latinoamericana de la Industria Petrolera (2008) 'Historia del Petróleo En Colombia', p. 4.

Avellaneda, A. (2003) 'Petróleo, ambiente y conflicto en Colombia', Guerra Sociedad y Medio Ambiente. Edited by F. N. Ambiental. Foro Nacional Ambiental, pp. 455-501. Available at: http://library.fes.de/pdffiles/bueros/kolumbien/01993/01.pdf.

Ayantobo, O. O. et al. (2017) 'Spatial comparability of drought characteristics and related return periods in mainland

China over 1961-2013', Journal of Hydrology, 550, pp. 549-567. doi: 10.1016/j.jhydrol.2017.05.019.

Badjana, H. M. et al. (2017) `Hydrological system analysis and modelling of the Kara River basin (West Africa) using a lumped metric conceptual model', Hydrological Sciences Journal, 62(7). doi: 10.1080/02626667.2017.1307571.

Ballinas-González, H. A., Alcocer-Yamanaka, V. H. and Pedrozo-Acuña, A. (2016) ‘Uncertainty analysis in datascarce urban catchments', Water (Switzerland), 8(11). doi: 10.3390/w8110524.

285 Bellin, A. et al. (2016) 'A continuous coupled hydrological and water resources management model', Environmental Modelling and Software. Elsevier Ltd, 75, pp. 176-192. doi: 10.1016/j.envsoft.2015.10.013.

Beven, K. and Freer, J. (2001a) 'A dynamic TOPMODEL', Hydrological Processes. John Wiley \& Sons, Ltd., 15(10), pp. 1993-2011. doi: 10.1002/hyp.252.

Beven, K. and Freer, J. (2001b) `Equifinality, data assimilation, and uncertainty estimation in mechanistic modelling 290 of complex environmental systems using the GLUE methodology', Journal of Hydrology, 249(1-4), pp. 11-29. doi: 10.1016/S0022-1694(01)00421-8.

Blanco-Gutiérrez, I., Varela-Ortega, C. and Purkey, D. R. (2013) 'Integrated assessment of policy interventions for promoting sustainable irrigation in semi-arid environments: a hydro-economic modeling approach.', Journal of environmental management, 128, pp. 144-60. doi: 10.1016/j.jenvman.2013.04.037.

295 Boskidis, I. et al. (2012) ‘Hydrologic and Water Quality Modeling of Lower Nestos River Basin', Water Resources 
Management, 26(10), pp. 3023-3051. doi: 10.1007/s11269-012-0064-7.

Bossa, A. Y. et al. (2012) 'Modeling the effects of crop patterns and management scenarios on $\mathrm{N}$ and $\mathrm{P}$ loads to surface water and groundwater in a semi-humid catchment (West Africa)', Agricultural Water Management, 115, pp. 20-37. doi: 10.1016/j.agwat.2012.08.011.

300 Buytaert, W. (2011) 'topmodel: Implementation of the hydrological model TOPMODEL in R', Global Change Biology, pp. 679-706. doi: 10.1111/j.1365-2486.2006.01305.x.

Buytaert, W. and Beven, K. (2011) 'Models as multiple working hypotheses: hydrological simulation of tropical alpine wetlands', Hydrological Processes. John Wiley \& Sons, Ltd., 25(11), pp. 1784-1799. doi: 10.1002/hyp.7936.

Crespo, P. et al. (2012) 'Development of a conceptual model of the hydrologic response of tropical Andean micro305 catchments in Southern Ecuador', Hydrology and Earth System Sciences Discussions, 9(2), pp. 2475-2510. doi: 10.5194/hessd-9-2475-2012.

Dai, H. et al. (2017) 'A new process sensitivity index to identify important system processes under process model and parametric uncertainty', Water Resources Research, 53(4). doi: 10.1002/2016WR019715.

Dakhlaoui, H. et al. (2017) `Evaluating the robustness of conceptual rainfall-runoff models under climate variability 310 in northern Tunisia', Journal of Hydrology. Elsevier B.V., 550, pp. 201-217. doi: 10.1016/j.jhydrol.2017.04.032.

Devi, G. K., Ganasri, B. P. and Dwarakish, G. S. (2015) 'A Review on Hydrological Models', Aquatic Procedia, 4, pp. 1001-1007. doi: 10.1016/j.aqpro.2015.02.126.

Dewandel, B. et al. (2017) 'Inferring the heterogeneity, transmissivity and hydraulic conductivity of crystalline aquifers from a detailed water-table map', Journal of Hydrology, 550, pp. 118-129. doi: 10.1016/j.jhyd rol.2017.03.075.

315 Díaz, C., Esteller, M. and Lopez-Vera, F. (2005) Recursos Hídricos. Conceptos básicos y estudio de caso en iberoamerica.

Dunne, T. (1983) 'Relation of field studies and modeling in the prediction of storm runoff', Journal of Hydrology, 65(1), pp. 25-48. doi: 10.1016/0022-1694(83)90209-3.

Gil Morales, E. G. and Tobón Marín, C. (2016) ‘Hydrological modelling with TOPMODEL of Chingaza páramo, Colombia', Revista Facultad Nacional de Agronomía, 69(2). doi: 10.15446/rfna.v69n2.59137.

320 Hargreaves, G. H. and Allen, R. G. (2003) 'History and Evaluation of Hargreaves Evapotranspiration Equation', Journal of Irrigation and Drainage Engineering, 129(1).

Hargreaves, G. H. and Samani, Z. A. (1982) 'Estimating potential evapotranspiration', Journal of the Irrigation $\mathcal{E}$ Drainage Division, 108(IR3), pp. 225-230.

Harou, J. J. et al. (2009) 'Hydro-economic models: Concepts, design, applications, and future prospects', Journal of Hydrology, 375(3-4), pp. 627-643. doi: 10.1016/j.jhydrol.2009.06.037. 
He, L. et al. (2012) 'Quasi-Monte Carlo based global uncertainty and sensitivity analysis in modeling free product migration and recovery from petroleum-contaminated aquifers.', Journal of hazardous materials, 219-220, pp. 133-40. doi: 10.1016/j.jhazmat.2012.03.067.

van der Heijden, S. and Haberlandt, U. (2015) 'A fuzzy rule based metamodel for monthly catchment nitrate fate simulations', Journal of Hydrology. Elsevier B.V., 531, pp. 863-876. doi: 10.1016/j.jhydrol.2015.10.039.

Hollanda, M. P. et al. (2015) 'Evaluation of TOPMODEL for prediction of the runoff of a watershed under different land uses I Avaliação do TOPMODEL na estimativa do escoamento superficial em microbacia hidrográfica em diferentes usos', Revista Brasileira de Engenharia Agricola e Ambiental, 19(5). doi: 10.1590/18071929/agriambi.v19n5p489-496.

335 Hughes, D. A. (2016) 'Hydrological modelling, process understanding and uncertainty in a southern African context: lessons from the northern hemisphere', Hydrological Processes, 30(14). doi: 10.1002/hyp.10721.

Ibarra-Zavaleta, S. P. et al. (2017) 'Distributed hydrological modeling: Determination of theoretical hydraulic potential \&amp; streamflow simulation of extreme hydrometeorological events', Water (Switzerland), 9(8). doi: $10.3390 /$ w9080602.

340 Ideam (2014) Estudio Nacional del Agua 2014.

Jaime Herrera, B. et al. (2013) Cadena De Petroleo 2013, Unidad de Planeación Minero Energética.

Jenson, S. K. (1991) 'Applications of hydrologic information automatically extracted from digital elevation models', Hydrological Processes, 5(1), pp. 31-44. doi: 10.1002/hyp.3360050104.

Jeziorska, J. and Niedzielski, T. (2018) 'Applicability of TOPMODEL in the mountainous catchments in the upper 345 Nysa Kłodzka river basin (SW Poland)', Acta Geophysica, 66(2), pp. 203-222. doi: 10.1007/s11600-018-0121-6.

Karlsson, I. B. et al. (2016) 'Combined effects of climate models, hydrological model structures and land use scenarios on hydrological impacts of climate change', Journal of Hydrology, 535, pp. 301-317. doi: 10.1016/j.jhydrol.2016.01.069.

Kauffeldt, A. et al. (2016) 'Technical review of large-scale hydrological models for implementation in operational 350 flood forecasting schemes on continental level', Environmental Modelling \& Software, 75, pp. 68-76. doi: 10.1016/j.envsoft.2015.09.009.

Lamb, R., Beven, K. and Myrabø, S. (1998) 'Use of spatially distributed water table observations to constrain uncertainty in a rainfall-runoff model', Advances in Water Resources, 22(4), pp. 305-317. doi: 10.1016/S03091708(98)00020-7.

355 Loosvelt, L. et al. (2014) 'Assessing hydrologic prediction uncertainty resulting from soft land cover classification', Journal of Hydrology, 517, pp. 411-424. doi: 10.1016/j.jhydrol.2014.05.049. 
Mazzoleni, M. et al. (2015) 'Assimilating uncertain, dynamic and intermittent streamflow observations in hydrological models', Advances in Water Resources, 83, pp. 323-339. doi: 10.1016/j.advwatres.2015.07.004.

Meerveld, I. T. van and Weiler, M. (2008) 'Hillslope dynamics modeled with increasing complexity', Journal of Hydrology, 361(1-2), pp. 24-40. doi: 10.1016/j.jhydrol.2008.07.019.

Metcalfe, P., Beven, K. and Freer, J. (2015) 'Dynamic TOPMODEL: A new implementation in R and its sensitivity to time and space steps', Environmental Modelling and Software, 72. doi: 10.1016/j.envsoft.2015.06.010.

Mockler, E. M., O'Loughlin, F. E. and Bruen, M. (2016) 'Understanding hydrological flow paths in conceptual catchment models using uncertainty and sensitivity analysis', Computers \& Geosciences, 90, pp. 66-77. doi: 365 10.1016/j.cageo.2015.08.015.

Mukherjee, S. et al. (2013) 'Evaluation of topographic index in relation to terrain roughness and DEM grid spacing', Journal of Earth System Science, 122(3).

Padrón, R. S. et al. (2015) 'Rainfall in the Andean Páramo: New Insights from High-Resolution Monitoring in Southern Ecuador', Journal of Hydrometeorology, 16(3), pp. 985-996. doi: 10.1175/JHM-D-14-0135.1.

370 Refsgaard, J. C. (1997) 'Parameterisation, calibration and validation of distributed hydrological models', Journal of Hydrology, 198(1-4), pp. 69-97. doi: 10.1016/S0022-1694(96)03329-X.

Reynaud, A. and Leenhardt, D. (2008) ‘MoGIRE : A Model for Integrated Water Management', American Geophysical Union, 2, pp. 576-583.

Ruelland, D. et al. (2008) 'Sensitivity of a lumped and semi-distributed hydrological model to several methods of rainfall interpolation on a large basin in West Africa', Journal of Hydrology. Elsevier B.V., 361(1-2), pp. 96-117. doi: 10.1016/j.jhydrol.2008.07.049.

Salazar, J. (2016) Una metodología para la estimación de curvas de duración de caudales (cdc) en cuencas no instrumentadas. Caso de aplicación para Colombia en los departamentos de Santander y norte de Santander.

Sharma, A., Tiwari, K. N. and Bhadoria, P. B.S. (2011) 'Determining the optimum cell size of digital elevation model for hydrologic application', Journal of Earth System Science, 120(4).

Sieber, J. et al. (2005) 'WEAP a demand, priority, and preference driven water planning model: Part 1, model characteristics', Water International, 30(4), pp. 487-500. doi: 10.1080/02508060508691893.

Sigdel, A. et al. (2011) 'Applicability of TOPMODEL in the catchments of nepal: Bagmati river basin', Geosystem Engineering, 14(4), pp. 181-190. doi: 10.1080/12269328.2011.10541349.

385 da Silva, M. G. et al. (2015) 'Sensitivity Analysis and Calibration of Hydrological Modeling of the Watershed Northeast Brazil', Journal of Environmental Protection. Scientific Research Publishing, 6(8), pp. 837-850. doi: 10.4236/jep.2015.68076. 
Simmons, J. A. et al. (2017) 'Calibrating and assessing uncertainty in coastal numerical models', Coastal Engineering, 125. doi: 10.1016/j.coastaleng.2017.04.005.

390 Suliman, A. H. A. et al. (2016) 'TOPMODEL for Streamflow Simulation of a Tropical Catchment Using Different Resolutions of ASTER DEM: Optimization Through Response Surface Methodology', Water Resources Management, 30(9). doi: 10.1007/s11269-016-1338-2.

Teng, J. et al. (2017) 'Flood inundation modelling: A review of methods, recent advances and uncertainty analysis', Environmental Modelling and Software, 90. doi: 10.1016/j.envsoft.2017.01.006.

395 Tian, Y., Zheng, Y. and Zheng, C. (2016) 'Development of a visualization tool for integrated surface watergroundwater modeling', Computers \& Geosciences, 86, pp. 1-14. doi: 10.1016/j.cageo.2015.09.019.

Wagner, P. D. et al. (2012) 'Comparison and evaluation of spatial interpolation schemes for daily rainfall in data scarce regions', Journal of Hydrology. Elsevier B.V., 464-465, pp. 388-400. doi: 10.1016/j.jhydrol.2012.07.026.

Wiant, H. V. J. and Harner, E. J. (1979) ‘Percent Bias and Standard Error in Logarithmic Regression', Forest Science, 400 25(1), pp. 167-168.

Wu, Q. et al. (2017) 'Improvement of hydrological model calibration by selecting multiple parameter ranges', Hydrology and Earth System Sciences, 21(1). doi: 10.5194/hess-21-393-2017.

Xue, L. et al. (2018) 'Hydrological simulation and uncertainty analysis using the improved TOPMODEL in the arid Manas River basin, China', Scientific Reports. Springer US, 8(1), pp. 1-12. doi: 10.1038/s41598-017-18982-8.

405 Yi, L., Zhang, W.-C. and Yan, C.-A. (2017) 'A modified topographic index that incorporates the hydraulic and physical properties of soil', Hydrology Research, 48(2). doi: 10.2166/nh.2016.119.

Zhang, Y. et al. (2016) 'Multi-metric calibration of hydrological model to capture overall flow regimes', Journal of Hydrology, 539, pp. 525-538. doi: 10.1016/j.jhydrol.2016.05.053.

Zhang, Z. et al. (2016) 'Modeling spatiotemporal dynamics of global wetlands: Comprehensive evaluation of a new 410 sub-grid TOPMODEL parameterization and uncertainties', Biogeosciences, 13(5). doi: 10.5194/bg-13-1387-2016. 